\title{
Sustainable Energy Management Design for Bario Microgrid in Sarawak, Malaysia
}

\author{
Adila Fakhar \\ Department of Electrical and Electronic \\ Faculty of Engineering \\ Universiti Malaysia Sarawak \\ Kota Samarahan, Sarawak, Malaysia
}

\author{
Ahmed M. A. Haidarab \\ ${ }^{a}$ Universiti Malaysia Sarawak \\ Kota Samarahan, Sarawak, Malaysia \\ bUniversity of Southern Queensland \\ Toowoomba, Queensland, Australia
}

\author{
Musse M. Ahmed, A. K. Rahman \\ Department of Electrical and Electronic \\ Faculty of Engineering \\ Universiti Malaysia Sarawak \\ Kota Samarahan, Sarawak, Malaysia
}

\begin{abstract}
The use of diesel generators as a backup to supply the load demand in Bario is costly and environmentally troublesome. On the other hand, utilizing natural resources that form islanded microgrids located in different areas can pose peculiar energy management issues, particularly, when different energy providers manage the renewable and nonrenewable small powerhouses. This paper proposes a framework focusing on the design of sustainable aggregate management system for minimizing the operating time of diesel generators, and thus, reducing the fuel cost and increasing the battery lifetime, while at the same time protecting the environment. Initially, the paper discusses the structure of the existing system. Further, an energy management approach is presented for maximizing the generated power from the available renewable resources at different hours. The presented results show that the proposed sustainable design can be an effective method for planning the development of electrification in the rural areas of Sarawak.
\end{abstract}

Keywords-Bario microgrid, energy management, integrated renewable resources, energy storage, cost optimization

\section{INTRODUCTION}

The economic growth of Sarawak mainly depends on the sufficient renewable energy to accommodate the increasing demand, as this can help in reducing the environmental impacts from the conventional power generation. Since many remote areas in Sarawak would not be possible connecting them with the power grid in the future, using the local renewable energy resources (RER) with a certain capacity of energy storage devices, can meet the growing need of electricity in such areas [1]. The Sarawak Alternative Rural Electrification Scheme (SARES) was launched in 2016 to speed up the efforts towards full electrification in Sarawak. This initiative by the State Government aims to provide 24hour electricity supply through the utilization of RER. Due to the extremely rugged and challenging terrain in some rural areas of Sarawak, such as Bario, extending the transmission power lines to these areas is a daunting task and needs huge investment. Therefore, Sarawak Energy Berhad (SEB) has built a hybrid microgrid system to fulfil the load demand in Bario. Indeed, some small-scale hydropower projects previously established in Bario as demonstrated in Table 1 [1], [2]. However, these projects lack the entire ability for the intelligent integration with the current hybrid microgrid in Bario. Furthermore, the energy storage coordination and demand response implementation did not receive yet any attention in the existing systems, or even in the planned projects by SEB. Owing to the intermittent nature of RER, the reliability of standalone microgrids installed in the remote areas of Sarawak is a major issue, as this is the main

This work has been supported by FRGS grant (F02/FRGS/1497/2016), Ministry of Higher Education (Malaysia). reason of power shortage during the peak time. Additionally, the high production from RER depends on the place, time, climate and weather conditions.

Bario is located in Miri division about $178 \mathrm{~km}$ to the east of Miri on a mountainous terrain at 3200 feet above the sea level. Thus, making it an isolated place and impossible to be linked with the main grid [3]. Bario consists of several villages with an area of $3850 \mathrm{~km}^{2}$. The location of Bario with the connected areas to electricity is shown in Fig. 1. The readily available natural resources are being used by the local communities with the government participation, as the target of SARES until 2020 is to electrify more than 300 remote villages. Despite the low population in Bario, it is expected an increase in tourist influx during the summer season and growth in agriculture and transportation sectors. This will result in raising the electricity consumption to above $1 \mathrm{MW}$. As seen from Fig. 1, for the electrification of remote areas, where the power grid is impossible and uneconomical to reach there, microgrid implementation using the local natural resources is the best solution. However, the cost of such system cannot be justified without optimal utilization of the available RER. Therefore, a techno-economic analysis should be carried out to find the best configuration with the highest achievable performance, while considering the constraints of system security [4]. Further, it is crucial to increase the generation from RER in order to minimize the charging cycles of the batteries. This aim can be achieved by applying smart energy management, either from the demand side by implementing a load control approach (modifying or shifting the demand profile [5]), or from the generation side by utilizing the coordination of small-scale energy projects (integrate them into a hybrid microgrid structure).

Several energy management approaches for demand-side control are reported in the literature. A fuzzy-multi criterion decision-making approach was proposed in [5]. The authors considered the demand side control to fill the gap between the continuously increasing demand and the available power supply. A smart energy management system based on minimizing the operating cost was presented in [6]. The proposed algorithm involves the management of RER with real-time energy forecasting, controllable loads and energy storage control. Load shifting by heat pumps based on overheating the stored hot water was proposed in [7]. The technique can result in decreasing the electricity cost, but this system causes an increase in the daytime and late-night temperatures. In addition, the instability issues with hardware and controllable interface are the main concerns in this system. A fast control method was applied by [8] to manage the domestic loads in a standalone microgrid. Authors in [8] did not provide any information about the type of resources connected to the microgrid, efficiency of the system and load factor. 